\title{
Encapsulated Thermoelectric Modules and Compliant Pads for Advanced Thermoelectric Systems
}

\author{
MITSURU KAMBE, ${ }^{1,3}$ TAKAHIRO JINUSHI, ${ }^{2}$ and ZENZO ISHIJIMA ${ }^{2,4}$ \\ 1.-Central Research Institute of Electric Power Industry (CRIEPI), 11-1, Iwado Kita 2-chome, \\ Komae-shi, Tokyo 201-8511, Japan. 2.-Hitachi Chemical Co., Ltd., 2-1, 5-chome, Minoridai, \\ Matsudo-shi, Chiba 270-2295, Japan. 3.-e-mail: kambe@criepi.denken.or.jp. 4.-e-mail: \\ zshijima@hitachihem.co.jp
}

The described encapsulated thermoelectric (TE) module consists of a vacuumtight stainless-steel container with dimensions of $55 \mathrm{~mm} \times 50 \mathrm{~mm} \times 11 \mathrm{~mm}$ in which a $\mathrm{SiGe}$ or BiTe TE module is placed. This construction enables maximum performance and durability because: (1) the thermal expansion mismatch between the hot and cold sides of the container can be accommodated by a sliding sheet that is present in the container; (2) the TE module inside is always kept in a vacuum environment so that oxidation cannot occur; and (3) the difference in pressure between the inside and outside of the container reduces the thermal contact resistance inside the container. The design also includes a compliant pad made of porous material that is infiltrated with braze filler material. If heated to a temperature above the melting temperature of the braze filler, the thermal gap conductance of the interface is enhanced due to the strong affinity of the braze filler to an adjacent member. It is possible for this interface to slide as long as the braze filler is in the liquid state. This design strategy provides high-flux, direct conduction paths to the heat source and heat sink as well as a large temperature gradient across the TE module itself (1.7 times that in the case of the conventional design strategy); therefore, the module can provide a power output that is three times greater than that of a conventional module.

Key words: Thermoelectric module, silicon-germanium, bismuth telluride, compliant pad

\section{INTRODUCTION}

In the development of thermoelectric (TE) systems, in addition to the semiconductor material, the $\mathrm{TE}$ module and heat exchanger system play important roles in achieving high system conversion efficiency and high durability.

A conventional multicouple TE module is usually sandwiched between electrically insulating base plates to protect sensitive semiconductor elements. In the operating temperature range, however, dome-shaped deformation of the TE module due to differential thermal expansion between the hot and cold base plates results in severe thermal stress in

(Received June 5, 2009; accepted June 20, 2010;

published online July 23, 2010) the TE module. Another design that is available is a skeleton module in which there is an electrically insulating base plate on one side and the other side is open. If the base plate is attached to the colder side, it is easier to relieve the thermal stress in the module. However, this module is very fragile. Therefore, most modules in standard products on the market have two base plates. To relieve the thermal stress in the module completely and to achieve high durability, the present authors have developed an encapsulated TE module, i.e., a bothside-skeleton module, that is encapsulated. In this paper, the structure of the encapsulated module is presented and its performance discussed.

In most TE systems used in terrestrial applications, TE modules with an applied pressure load are placed between a hot duct (heat source) and a cold 
duct (heat sink). This is called "conduction coupling." This configuration gives rise to two contradictory problems: (1) In the operating temperature range, the differential thermal expansion between the hot and cold ducts must be accommodated without inducing large stress in the TE module; therefore, a moderate pressure load is preferred. (2) On the other hand, the thermal contact resistance at the TE module-duct interface should be minimized, since it would lead to low electrical output. Increasing the pressure load would reduce the thermal resistance; however, it would damage the fragile TE modules. In view of these problems, the present authors have proposed bond-free compliant pads ${ }^{1}$ to accommodate greater thermal expansion mismatch and severe thermal transients. The structure, properties, and performance of the bond-free compliant pad are also discussed herein.

\section{ENCAPSULATED THERMOELECTRIC MODULES}

\section{Encapsulated Thermoelectric Module for Space and High-Temperature Applications}

The encapsulated TE module (Fig. 1) consists of a vacuum-tight stainless-steel container with dimensions of $55 \mathrm{~mm} \times 50 \mathrm{~mm} \times 11 \mathrm{~mm}$ in which a SiGe TE module is placed. In the container, mica sheets for electrical insulation and carbon sheets to accommodate the differential thermal expansion are also inserted on both sides of the module. Because this module has no electrically insulating base plate, perfect thermal stress relief in the module is achieved. However, a both-side-skeleton module is very fragile, and considerable attention should be paid to such modules during their assembly and encapsulation. Therefore, a systematic handling procedure and holders for use during module brazing, assembly, and welding have been developed. Once encapsulated, the interior of the container is a vacuum because the electron-beam welding of the container is carried out in a vacuum chamber. Accordingly, the module is stably positioned inside the container due to a pressure difference of $1 \mathrm{bar}$ $(0.1 \mathrm{MPa})$ exerted on the $0.1-\mathrm{mm}$-thick top surface of the container. This pressure reduces the thermal contact resistance between members in the container.

Another advantage of encapsulation is that the module itself is always kept in a vacuum, even though the container might be placed in hot air or a corrosive atmosphere, which would be the case in applications where TE modules make use of industrial waste heat or automobile exhaust gas. Hence, encapsulation enhances the durability of the TE semiconductor, which is very sensitive to humidity, oxidation, and corrosion. Our encapsulated SiGe module features a higher operating temperature: up to $650^{\circ} \mathrm{C}$ for both the hot and cold sides. The module performance is shown in Fig. 2. The module can withstand 1400 heat cycles at $550^{\circ} \mathrm{C}$, which shows its high durability.

In addition, an encapsulated BiTe module is also available. The BiTe module adopted in the present study is a one-side-skeleton module, because the thermal expansion mismatch is not significantly greater than that in the SiGe module. The operating temperature range of the former module is $180^{\circ} \mathrm{C}$ to $190^{\circ} \mathrm{C}$ for both the hot and cold sides. ${ }^{2}$

According to our experiments, the power output of the encapsulated module is 0.84 times greater than that of the module without encapsulation. This means that the temperature gradient of the former module is 0.92 times greater than that of the latter module (i.e., $0.92^{2}=0.84$ ). A thermal shunt between the hot and cold sides of the container and the thermal contact resistance in the container are

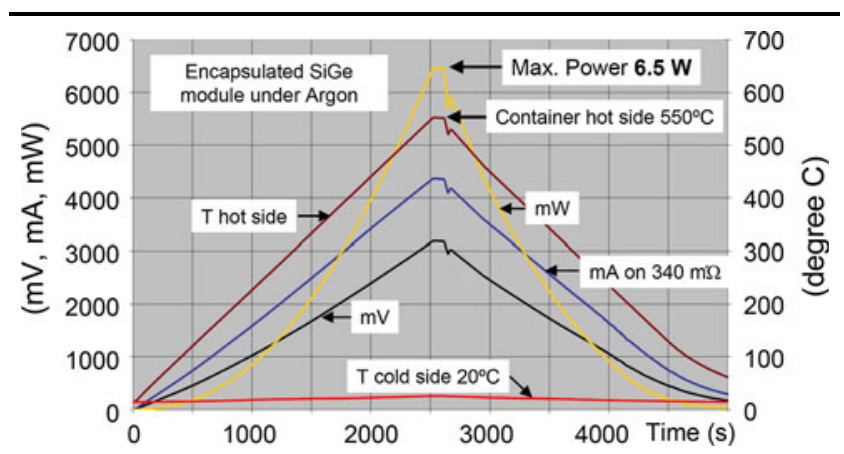

Fig. 2. Encapsulated SiGe module performance.

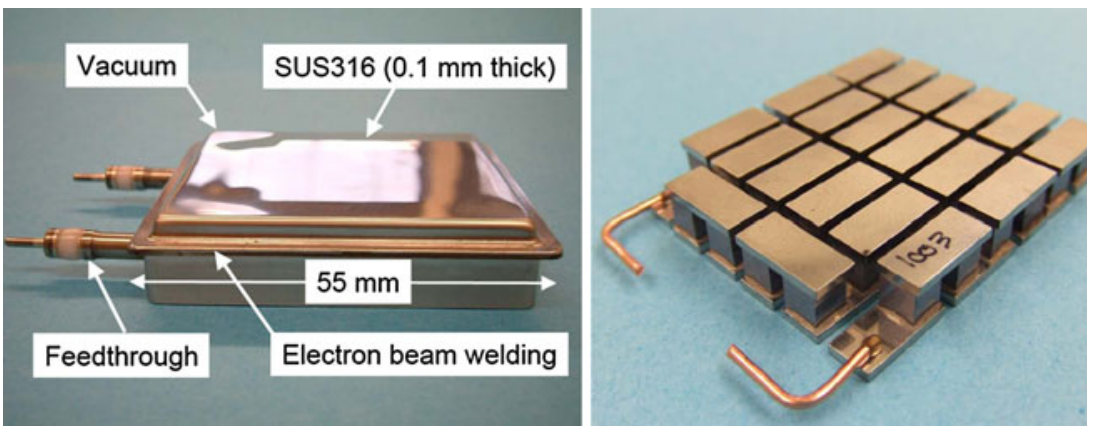

Fig. 1. Encapsulated TE module (left, SiGe or BiTe) in which the SiGe module (right) is encased. 
responsible for the decrease in the module power. Despite such disadvantages, encapsulation is necessary to ensure module integrity and high durability.

\section{Encapsulated Thermoelectric Module with Integrated Cooling Panel}

This module is provided with an integrated cooling panel through which cooling water can pass. When the hot side of the module is heated by a radiating heat source (radiation coupling) or convection of a hot gas or fluid (convection coupling), it is not necessary to apply a pressure force on the module. The encapsulated TE module shows minimum contact resistance to the cooling duct when the pressure force is absent, which results in maximum TE power and minimum installation cost (Fig. 3).

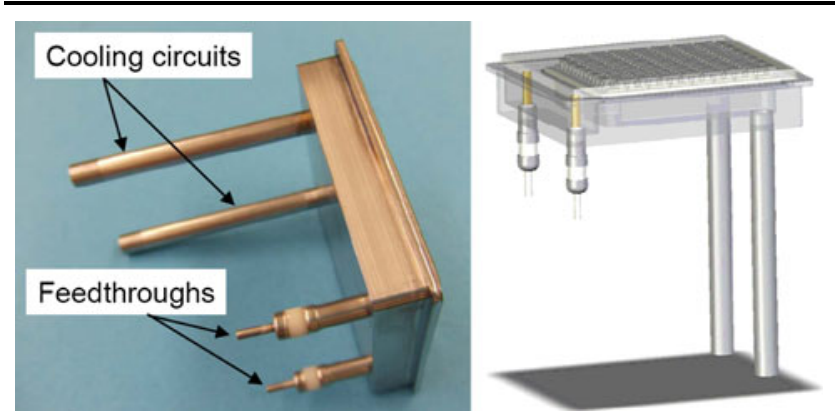

Fig. 3. Encapsulated TE module with integrated cooling panel.

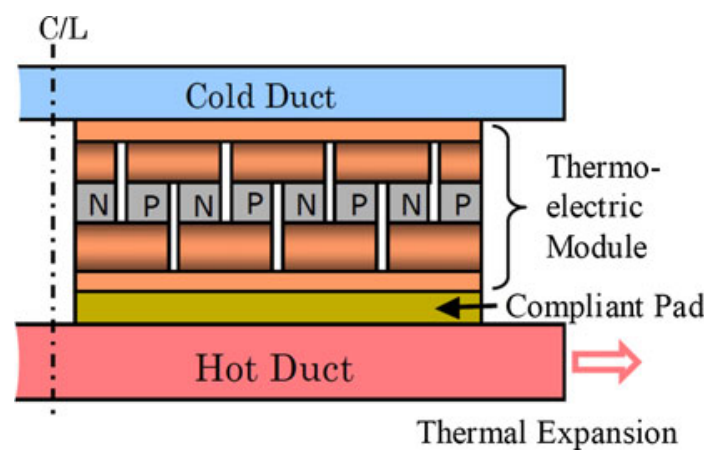

Fig. 4. Bond-free compliant pad concept.

\section{COMPLIANT PADS}

The greater the capacity of the TE energy conversion system, the larger the heating and cooling ducts between which the TE modules are clamped. In addition, the operating temperature of TE power conversion systems used in space applications is generally higher than that of systems used in terrestrial applications. A bond-free compliant pad (BFCP $^{1,3}$ should be used to accommodate a severe thermal expansion mismatch parallel to the duct surface (Fig. 4). The BFCP is made of porous material that is infiltrated with braze filler material. If heated to a temperature above the melting temperature of the braze filler, the thermal gap conductance of the interface is enhanced due to the strong affinity of the braze filler to an adjacent member. It is possible for this interface to slide as long as the braze filler is in the liquid state. The advantage of this concept is that the braze filler comes out of the pores continuously to compensate for loss of braze filler on the surface, which is mainly due to vaporization. The thermal gap conductance therefore retains its initial value. In this way, high durability can be ensured. The following BFCPs have been manufactured and tested so far.

- Bismuth (melting temperature: $271^{\circ} \mathrm{C}$ ) infiltrated in oriented carbon fibers (Bi/C) (Fig. 5).

- CB2 braze filler (trade name of Goodfellow GmbH; 96Ag-4Ti; melting temperature: $970^{\circ} \mathrm{C}$ ) infiltrated in oriented carbon fibers for use in space systems $(\mathrm{CB} 2 / \mathrm{C})^{3}$

- Bismuth infiltrated in porous copper $(\mathrm{Bi} / \mathrm{Cu})$.

- Salt $\left(\mathrm{NaNO}_{3} / \mathrm{KNO}_{3}\right.$; melting temperature: $\left.213^{\circ} \mathrm{C}\right)$ infiltrated in porous copper $(\mathrm{Salt} / \mathrm{Cu})$.

Figure 5 shows a Bi/C bond-free compliant pad with a thickness of $10 \mathrm{~mm}$. Bismuth is infiltrated by a squeeze-casting process into $80 \%$ density, oriented carbon fiber. The performance of the $\mathrm{Bi} / \mathrm{C}$ bond-free compliant pad is shown in Fig. 6. Due to the superior thermal conductivity of the carbon fiber in the longitudinal direction, the thermal conductivity of the pad normal to the contacting surface is also high. The effective thermal resistance of the pad (i.e., the thermal contact resistance of both contacting surfaces of the pad as well as the thermal resistance of the $10-\mathrm{mm}$-thick pad) suddenly
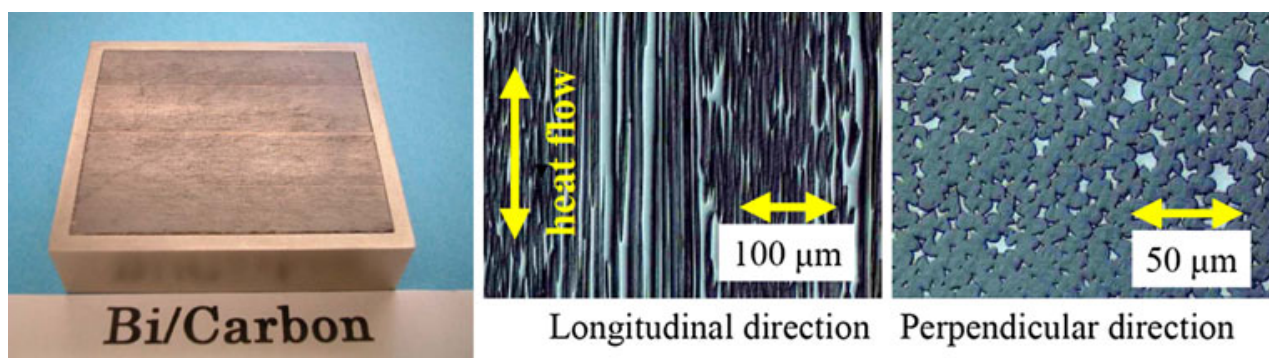

Longitudinal direction Perpendicular direction

Fig. 5. Bismuth infiltrated in carbon $(\mathrm{Bi} / \mathrm{C})$ bond-free compliant pad. 

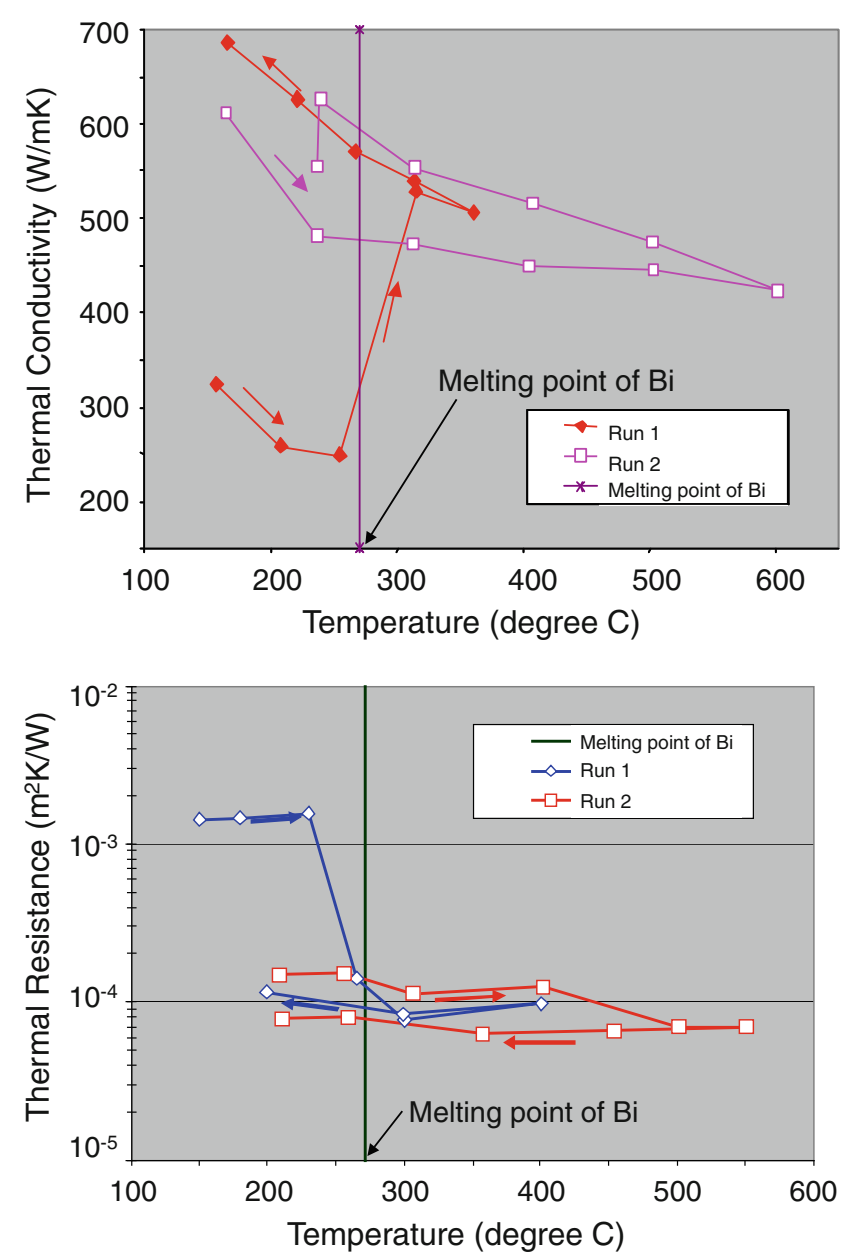

Fig. 6. Thermal conductivity (top) and effective thermal resistance (bottom) of the $\mathrm{Bi} / \mathrm{C} \mathrm{BFCP}$.

decreases by an order of magnitude if heated above the melting temperature of bismuth $\left(271^{\circ} \mathrm{C}\right)$.

The temperature distribution of TE modules with and without a compliant pad is shown in Fig. 7. A TE module with a bond-free compliant pad on the hot side and a carbon sheet on the cold side is shown on the left side. The carbon sheet that is $0.2 \mathrm{~mm}$ thick also acts as a compliant pad. It is applicable below $400^{\circ} \mathrm{C}$ in air. A conduction-coupling TE system with compliant pads provides high-flux, direct

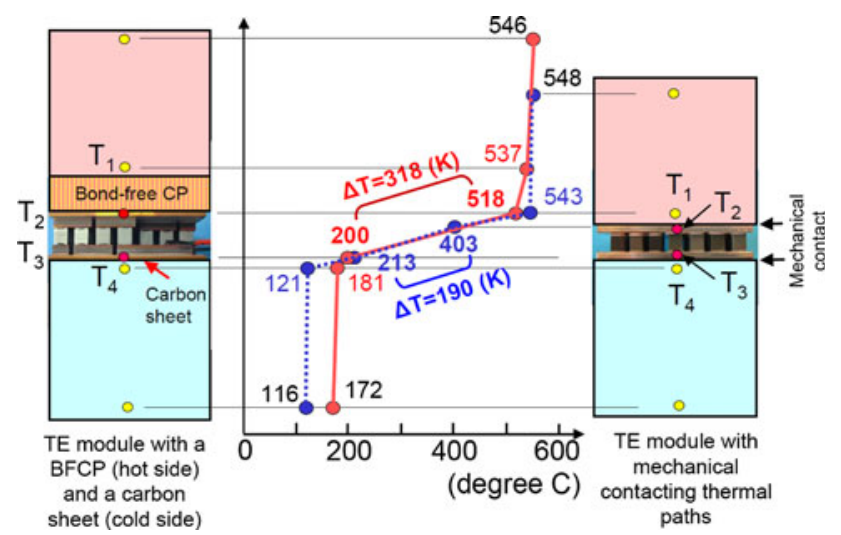

Fig. 7. Temperature distribution of the TE module with and without a bond-free compliant pad.

conduction paths to the heat source and heat sink, and a high temperature difference (i.e., $318 \mathrm{~K}$ instead of $190 \mathrm{~K}$ ) across the TE module itself; the temperature gradient of this system is greater than that in a conventional TE system, and therefore the former system can provide a power output that is three times that of the latter system. ${ }^{1}$

\section{CONCLUSIONS}

The encapsulated TE module and bond-free compliant pad provide high power and have high durability. Compared with mechanical contacts, the bond-free compliant pad can help increase the thermal gap conductance by an order of magnitude.

\section{OPEN ACCESS}

This article is distributed under the terms of the Creative Commons Attribution Noncommercial License which permits any noncommercial use, distribution, and reproduction in any medium, provided the original author(s) and source are credited.

\section{REFERENCES}

1. M. Kambe and H. Shikata, Acta Astronaut. 51, 161 (2002).

2. M. Kambe, R. Morita, K. Omoto, Y. Koji, T. Yoshida, and K. Noishiki, J. Power Energ. Syst. 2, 1304 (2009).

3. M. Kambe, H. Tsunoda, K. Nakajima, and T. Iwamura, J. Power Energ. 218, 335 (2004). 